\section{Evaluación de la empatía en medicina}

\section{Teaching and evaluating empathy in clinical practice}

\section{Sr Editor:}

Hemos leído con interés la publicación de Troncoso et $\mathrm{al}^{1}$, en el que se expone la importancia de las prácticas en la calidad de la enseñanza en el pregrado de Medicina $\mathrm{y}$ al hilo de sus reflexiones quisiéramos establecer una breve aportación.

Percibimos que la "empatía" hacia el paciente parece menos relevante en los planes docentes y ello es concordante con la escasa importancia que se le ha concedido como área de competencia.

En este sentido queremos señalar que el reducido impacto de la misma en el nivel docente puede comprobarse reseñando que en el prestigioso examen del Médico Interno Residente (MIR), durante los últimos 36 años, las cuestiones relativas a este ámbito de conocimiento se han situado entre las menos frecuentes. Hemos efectuado una revisión de las preguntas desde 1981 hasta 2017 y hemos encontrado sólo cinco relativas a "empatía", lo cual supone un porcentaje de 0,05\%: la 131 del MIR 2011, la 179, la 183 y la 187 del MIR 2015 y la 224 del MIR 2016². De ellas, cuatro tienen un enunciado breve (tres de dos líneas y una de cuatro) y la quinta se presenta como un caso clínico (doce líneas de enunciado).

Nuestro sistema de acceso a la formación de especialistas, por el que muchas de las generaciones que trabajamos actualmente hemos pasado, se reconoce como uno de los más transparentes y ecuánimes del mundo. El Ministerio de Sanidad, es justo reconocerlo, ha cuidado con esmero su nivel de excelencia ${ }^{3}$, sin embargo, el protagonismo de la "empatía" médico-paciente en comparación con otras materias a la hora de ser objeto de examen es ínfimo. Está ampliamente reconocido que aquello que no es objetivo de evaluación no suscita motivación para su estudio ${ }^{4}$ y por ello debiera incrementarse su protagonismo curricular.

De acuerdo con lo reiteradamente señalado por Moore et $\mathrm{al}^{5}$, los programas clínicos de educación debieran incluir la enseñanza de la comunicación médico-paciente. Resulta de extrema importancia en el desarrollo curricular cómo se aprenden las habilidades de comunicación. Prestigiosas instituciones de todo el mundo ${ }^{6}$ han abogado por el mantenido reto que supone reforzar la empatía en el contexto de la relación médico-paciente. En un intento de sistematización, tal y como refriere Kurtz ${ }^{7}$ la guía de observación de Calgary Cambridge ha sido usada en todos los niveles de la actividad médica, desde estudiantes de los primeros años hasta con los clínicos de mucha experiencia y en casi todas las especialidades y facilita el desarrollo sistemático de las habilidades comunicacionales. Constituye además una guía con considerable flexibilidad para permitir ser aplicada en médicos con estilos y personalidades muy diferentes. En nuestro país existen contribuciones alineadas con la que la que motiva este comentario $^{8}$ y otras de honda reflexión conceptual y aplicada en el área iberoamericana $a^{9,10}$ que abogan por la formación y evaluación activa en "empatía", área que se ha revelado como útil a la hora de optimizar la percepción que del médico tienen nuestros pacientes, que representan en definitiva el fin esencial de nuestra actividad profesional.

\section{José M. Eiros ${ }^{1}$, María Rosario Bachiller ${ }^{1}$, Tomás Villacampa ${ }^{2}$, Jaime Baladrón ${ }^{2}$ \\ ${ }^{1}$ Facultad de Medicina de Valladolid. ${ }^{2}$ Curso MIR Asturias. Oviedo. España.}

\section{Referencias}

1. Troncoso GD, Pérez VC, Vaccarezza GG, Aguilar AC, Muñoz NN. [The influence of pedagogic and discipline training on the teaching quality of university professors]. Rev Med Chile 2017; 145: 610-8.

2. https://sis.msssi.es/fse/[consultado el 13 de septiembre de 2017].

3. https://www.msssi.gob.es/eu/profesionales/formacion/home. htm [consultado el 9 de septiembre de 2017].

4. Guilbert JJ. Guía pedagógica para el personal de salud. Edición en español a cargo de Rodríguez Torres A, Carreres Quevedo J, Daufi Moreso L, Vilardell Viñas F. 5a ed. Valladolid: Instituto de Ciencias de la Educación, Universidad de Valladolid, ISBN 84-7762-062-8. 1989: 344 págs.

5. Moore P, Gómez G, Kurtz S. Comunicación médico-paciente: una de las competencias básicas pero diferentes. Aten Primaria 2012; 44: 358-65.

6. Association of American Medical Colleges. Medical School Objectives Project: Report III - Contemporary Issues in Medicine: Communication in Medicine. Association of American Medical Colleges; 1999.

7. Kurtz SM. Doctor patient communication: principles and practices. Can J Neurol Sci 2002; 29 Suppl 2: S23-9.

8. Díez-Goñi N, Rodríguez-Díez MC. Why teaching empathy is important for the medical degree. Rev Clin Esp 2017; 217: 332-5.

9. Petra-Micu I. La enseñanza de la comunicación en medicina. Inv Ed Med 2012; 1: 218-24.

10. Millán Núñez Cortés J. La enseñanza en el entorno clínico: un reto y una necesidad. Educación Médica 2017; 18 supl 1: 41-3. 